\title{
TOXICITY AND BLOOD AMMONIA RISE RESULTING FROM INTRAVENOUS AMINO ACID ADMINISTRATION IN MAN : THE PROTECTIVE EFFECT OF L-ARGININE
}

\author{
By JOHN L. FAHEY \\ (From the Metabolism Service, General Medicine Branch, National Cancer Institute, \\ National Institutes of Health, Bethesda, Md.)
}

(Submitted for publication October 17, 1956; accepted August 16, 1957)

A study of amino acid toxicity was undertaken following the observation that a mixture of intravenously administered L-amino acids that had been nutritionally adequate in a patient became toxic when L-arginine was deleted. This toxicity was unexpected for the amino acid mixture, even without arginine, contained all of the amino acids determined by Rose (1) to be essential to man. Readdition of L-arginine, however, prevented the toxicity. Subsequent studies by Guillino, Winitz, Birnbaum, Otey, Cornfield, and Greenstein suggested that the toxicity of arginine deficient L-amino acid mixtures might be attributable to a blood ammonia rise $(2,3)$.

Investigation of the arginine-deficient amino acid mixture in dogs (4) demonstrated a marked blood ammonia rise on intravenous administration and indicated that the toxic manifestations, convulsion and death were attributable to ammonia formation. L-arginine administration prevented the blood ammonia rise and toxicity.

The present studies were undertaken to demonstrate in man the blood ammonia rise that can develop from intravenous administration of an L-amino acid mixture deficient in arginine, and to confirm the capacity of L-arginine to significantly reduce the blood ammonia changes produced by this mixture. Glycine was also used to produce an elevation of blood ammonia, and the role of $\mathrm{L}$-arginine in preventing this rise was investigated.

\section{MATERIALS AND METHODS}

Solutions of amino acids containing all of the amino acids "essential" for man (1) were prepared so that each $250 \mathrm{ml}$. contained at least the minimal amount of all essential amino acids required for daily human maintenance (see Table I). 1 L-alanine was included to pro-

\footnotetext{
$1_{L}$-amino acids prepared by enzymic resolution (5) were generously supplied by members of the staff of the National Cancer Institute. Glycine was obtained from the Nutritional Biochemical Company, Cleveland, Ohio, and a portion of the L-arginine $\cdot \mathrm{HCl}$ was obtained from the Mann Research Laboratories, Inc., New York, N. Y.
}

vide nitrogen for synthesis of the nutritionally nonessential amino acids.

Individual 1.0 molar solutions of $\mathrm{L}$-arginine $\cdot \mathrm{HCI}$ and L-ornithine $\cdot \mathrm{HCl}$, and 1.7 molar solutions of glycine were prepared with pyrogen-free distilled water and sterilized in the autoclave. ${ }^{2}$ All solutions were tested by routine methods in the Division of Biologics Standards, National Institutes of Health, and found to be free of pyrogen and bacterial contaminants. Final concentration was checked by the Kjeldahl nitrogen determination.

Ammonia determination. Blood ammonia was determined on duplicate samples by a modification of the Seligson microdiffusion method $(6,7)$. Two and a half $\mathrm{ml}$. of blood are collected in a heparinized syringe, transferred to a clean test tube, and one ml. pipetted immediately into a $60 \mathrm{ml}$. wide-mouth serum bottle (U.S. Army Medical Corps Pattern) to which had previously been added $2 \mathrm{ml}$. of a saturated potassium carbonate solution. An etched glass rod mounted in a rubber stopper is dipped into $2 \mathrm{~N}$ sulfuric acid and promptly inserted into the bottle mouth. This entire operation, from appearance of blood in the syringe to stoppering of the bottle, requires about one minute. A blank preparation without blood is prepared at the same time. The bottles are then mounted on a 16 inch diameter diffusion wheel and rotated at 37 r.p.m. for 20 minutes. At the end of this time the glass rod is removed from the bottle and inserted into a Coleman 10 by $75 \mathrm{~mm}$. cuvette containing $3 \mathrm{ml}$. of a 1:10 dilution of Nessler's Reagent, inverted five times and removed, allowing drainage of the reagent from the rod. After 10 minutes at room temperature, the optical density at $\mathbf{4 2 0}$ millimicrons is read after setting the blank at zero density. With one microgram of ammonium nitrogen $\left(\mathrm{NH}_{2}-\mathrm{N}\right)$ the optical density was in the range of $\mathbf{0 . 0 6 5}$. Our experience is in agreement with that of Seligson $(6,7)$ with complete recovery of ammonia from ammonium sulfate standard solutions and 90 to 100 per cent recovery of ammonia added to blood. Each day a control curve was obtained by carrying out the entire procedure on samples of ammonium sulfate containing $1,2,5$ and 10 micrograms of $\mathrm{NH}_{3}-\mathrm{N}$. This curve is a straight line to 5 and tapers slightly to 10 micrograms of $\mathrm{NH}_{3}-\mathrm{N}$.

The mean fasting venous blood ammonia value of 80 determinations in seven individuals with localized neoplasms but without any evidence of liver disease fol-

2 These solutions were prepared with the assistance of Dr. J. A. Scigliano of the Pharmacy Department, Clinical Center, National Institutes of Health. 
TABLE I

Intravenous amino acid mixtures

\begin{tabular}{|c|c|c|}
\hline \multirow{2}{*}{ Amino Acid Composition } & \multicolumn{2}{|c|}{ Solutions } \\
\hline & B. 1 & B. 2 \\
\hline & (gms/Lt) & (gms/Lt) \\
\hline L.Tryptophone & 1.0 & 1.0 \\
\hline L.Phenylolonine & 4.4 & 4.4 \\
\hline L-Lysine & 3.4 & 3.4 \\
\hline L. Threonine & 2.0 & 2.0 \\
\hline L.Voline & 3.2 & 3.2 \\
\hline L. Methionine & 4.4 & 4.4 \\
\hline L. Leucine & 4.4 & 4.4 \\
\hline L. I soleveine & 2.8 & 2.8 \\
\hline L.Arginine & 4.4 & 0 \\
\hline L. Histidine & 4.4 & 0 \\
\hline L.Alonine & 112.8 & 120.4 \\
\hline
\end{tabular}

lowed for one to nine months with 4 to 23 determinations per patient was $1.1 \pm 0.2$ (S.D.) micrograms of $\mathrm{NH}_{2}-\mathrm{N}$ per $\mathrm{ml}$. The one subject who was followed for nine months with 23 determinations had a mean venous blood ammonia value of $1.2 \pm 0.2$ (S.D.) micrograms of $\mathrm{NH}_{2}-\mathrm{N}$ per ml. Similarly, single observations in 20 normal individuals averaged $1.2 \pm 0.2$ (S.D.) mg. $\mathrm{NH}_{2}-\mathrm{N}$ per ml.

Amino acid infusions. The arginine-free L-amino acid mixture was administered to four fasting subjects (M.M., J.F., W.P., D.G.) who had received their usual morning and noon diet, but the evening intake was free of protein on the day prior to study. Breakfast was omitted on the day of study. Glycine was infused into four subjects (G.S., W.P., J.F., G.A.) who had been fasted from protein while receiving adequate water, electrolytes and 300 grams glucose during the 36 hours prior to each study. The infusion studies generally were separated by a one week interval. One subject (W.M.) received glycine after dietary preparation as outlined above for the amino acid mixture.

The 60 minute infusions were administered through a Bowman constant infusion pump into a peripheral vein. Serial blood samples for ammonia determinations collected through a Cournand needle placed in an antecubital vein were obtained before, during, and after amino acid administration. Ammonia determinations were carried out immediately upon obtaining the blood. L-arginine was injected intravenously and separately from the amino acid infusion, unless otherwise noted. A total of 53 studies was carried out in seven subjects.

Subjects. All of the subjects who received amino acids intravenously presented significant problems in the maintenance of nutrition. All but one required either complete parenteral alimentation or cervical esophagastomy and intragastric tube feedings.

M.M., a 63 year old woman, had epidermoid carcinoma of the face. J.F. and G.S., respectively 56 and 55 year old men, had carcinoma of the buccal mucosa. W.P., a 42 year old man, and D.G., a 55 year old woman, had carcinoma of the stomach. G.A., a 59 year old man, had recurrent esophageal carcinoma, a liver palpable $3 \mathrm{~cm}$. below the right costal margin and normal liver function tests except for elevated alkaline phosphatase levels (4.5 to 9.2 Bodansky units), although at autopsy the 1,800 gram liver had no evidence of metastatic neoplasm. W.M., a 57 year old man with biopsy proven hepatoma that was symptomatic only through a painful mandibular metastasis, was found to have abnormal bromsulphalein retention ( 20 per cent), a 4 plus cephalin floculation test, thymol turbidity of $\mathbf{5}$ units, and an elevated serum globulin level, although the serum albumin, alkaline phosphatase and prothrombin time were normal. This patient is alive without evidence of hepatic failure eight months after these studies were performed.

Although all of the subjects had a malignant disease, none had evidence of renal or hematologic abnormality. Only W.P. and G.A. had lost weight prior to these observations, and only W.M. and G.A. had evidence of hepatic disease. Because these patients required intragastric tube feedings or entirely parenteral alimentation (except W.M.), dietary control was easily achieved. None lost weight during the period of experimental observation. None had edema, ascites or other evidence of fluid retention.

\section{RESULTS}

\section{Initial observation of amino acid toxicity}

In the course of observations on the nutritional value of amino acid mixtures administered intravenously as the sole source of nitrogen, a mixture of eight "essential" L-amino acids plus L-histidine, L-arginine and L-alanine was found to be non-toxic and nutritionally adequate in the patient who received this solution (Solution B-1, Table I). Positive nitrogen balance is demonstrated in Figure 1.

Another intravenous amino acid mixture (Solution B-2), essentially the same except for deletion of L-arginine and L-histidine, induced coma in this same patient. This $45 \mathrm{Kg}$. man, totally dependent on intravenous feeding because of multiple intestinal obstructions secondary to gastric carcinoma, during a period of six hours received 250 $\mathrm{ml}$. of this solution, which was sterile and pyrogen free. Two hours after the end of the infusion he was noted to be unresponsive. Neurologic examination revealed generalized rigidity, plastic resistance to passive movements, and bilateral Babinski responses. No definite localizing signs developed. Blood sugar and calcium levels obtained during coma were normal. Within 24 hours the patient became responsive to painful and auditory stimuli, and in another two days was entirely oriented and demonstrated normal motor function and reflexes. During this period of recovery, the 


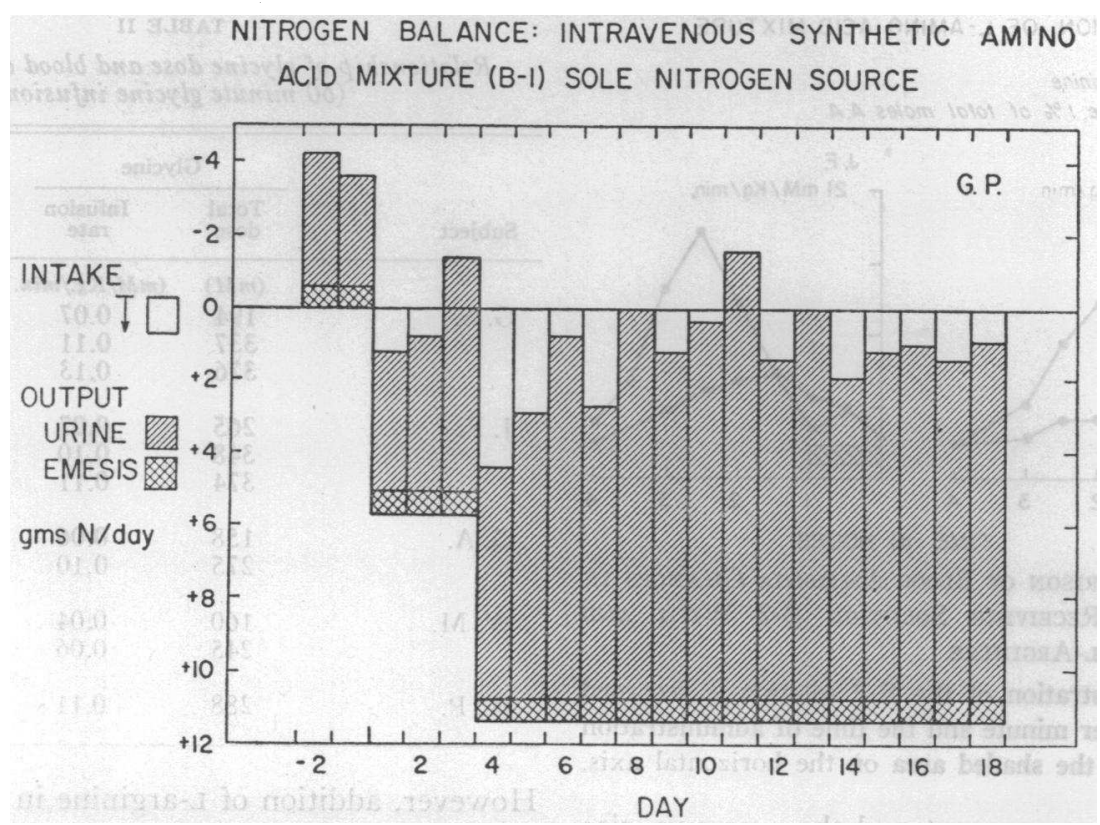

Fig. 1. Positive Nitrogen Balance in a Subject Receiving l-Amino Acid Mixture B-1 as Sole Source of Nitrogen

amino acid mixture containing L-arginine (B-1) was administered without evidence of toxicity. ${ }^{8}$

\footnotetext{
8 Because this episode differed somewhat from the toxic manifestations usually seen with transitory blood ammonia elevations, additional information may be of interest. Prior to this episode, there was no evidence of hepatic, renal or central nervous system disease. However, this patient had undergone a $24 \mathrm{Kg}$. weight loss in the previous two years, had been on a limited diet necessitated by the requirement for intravenous feeding during the preceding four months, and was in a state of mild folic acid deficiency (M.C.V., 105 cubic microns; hematocrit, 31 per cent; $B_{12}$ intake, adequate; marked [12 per cent] reticulocyte response to subsequent folic acid administration). Nausea and retching were noted in the two hours prior to the development of coma but similar symptoms had been present for several months and were attributed to the almost complete obstruction of the intestinal tract. This patient, when first seen in coma, had a respiratory rate of four per minute and had received four hours earlier $20 \mathrm{mg}$. of morphine sulfate, which represented a moderate increase in his regular narcotic medication. Because of the possibility of morphine poisoning, $10 \mathrm{mg}$. of allomorphine were given. Later, trembling movements of the head and extremities consistent with acute narcotic withdrawal became evident and gradually subsided over $\mathbf{3 0}$ hours. No tonic or clonic convulsions were observed. Fever developed 10 hours after the coma was first noted and persisted (daily peaks of 38.6 to $39.6^{\circ}$ C.) for five days, during which penicillin and tetracycline were given. Although a leukocytosis as high as 30,000 w.b.c. per cu. mm. was present during the first two days of fever and returned to
}

L-amino acid solution: Ammonia production and arginine protection

After extensive investigation in experimental animals of the changes associated with intravenous administration of the arginine deficient L-amino acid mixture (4), this solution was administered intravenously to subjects M.M. and J.F. with a resultant rise in blood ammonia (Figure 2). Addition of $\mathrm{L}$-arginine to the infusion mixture strikingly inhibited the ammonia rise. Quantities of L-arginine ( 6 and 7 millimoles) corresponding to only 1 per cent of the total amount of amino acids infused were effective. Observations in subject D.G. also revealed the same effect of L-arginine on the potential blood ammonia rise (Figure 3 ). Nausea and, rarely, retching were observed in association with blood ammonia over levels 6 $\mu \mathrm{g} . \mathrm{NH}_{\mathbf{3}}-\mathrm{N}$ per ml., but were definitely diminished

normal two days later, clinical, bacteriologic and roentgenographic studies revealed no evidence of an infection. During the 10 days following the coma episode, the nitrogen balance averaged -3.0 grams per day in contrast to $-0.4 \mathrm{gram}$ prior to this episode. The daily intake was 5.0 grams nitrogen and 1,200 calories in both periods. Other febrile episodes in this patient were not associated with such markedly negative nitrogen balances. At autopsy examination three months later, no organic brain disease was evident which might have accounted for this episode. 
INFUSION OF L-AMINO ACID MIXTURE

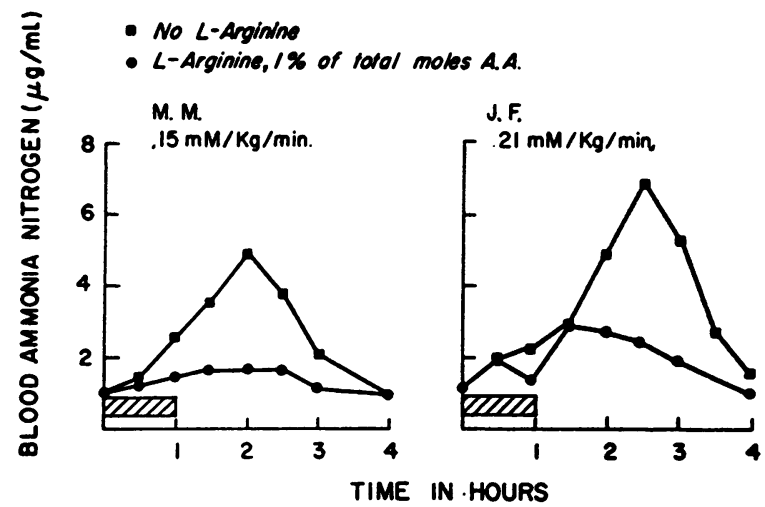

Fig. 2. Comparison of Blood Ammonia Changes in Two Subjects Receiving Solution B-2 With and WITHOUT ADDED L-ARGININE

Rate of administration of the B-2 solution is recorded in $\mathrm{mM}$ per $\mathrm{Kg}$. per minute and the time of administration is represented by the shaded area on the horizontal axis.

when arginine was present and the ammonia rise was reduced. No other toxic sign or symptom was noted.

These studies demonstrate the ammonia-forming potential of the toxic Solution B-2, an L-amino acid mixture that does not contain L-arginine.

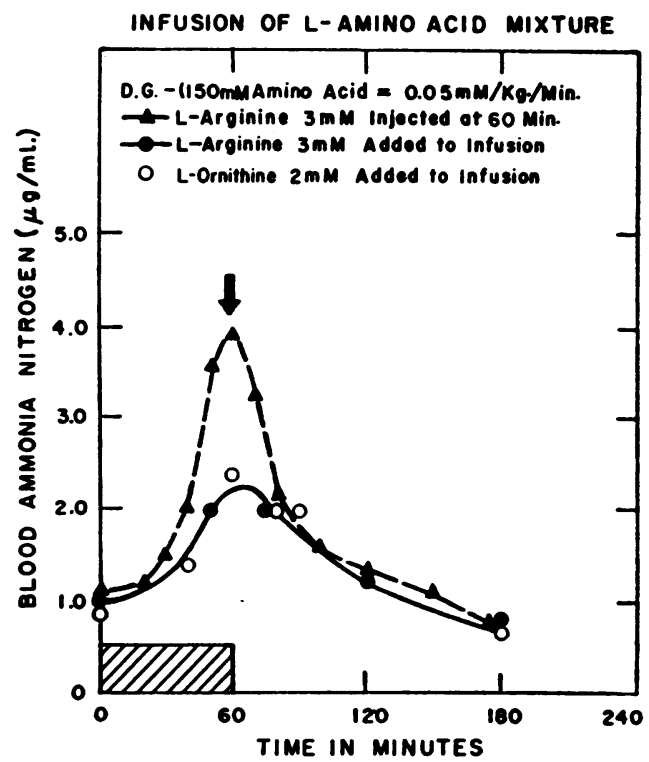

Fig. 3. Effret of L-Arginine and L-Ornithine on the Blood Ammonia Changes Associated With INfusion of Arginine-Deficient L-Amino ACID Mixture B-2

The shaded area indicates the time of amino acid (B-2) infusion. In one study the B-2 mixture was infused alone and arginine was injected intravenously, indicated by the arrow $(\downarrow)$, immediately afterward.
TABLE II

Relationship of glycine dose and blood ammonia rise (60 minute glycine infusion)

\begin{tabular}{|c|c|c|c|}
\hline \multirow[b]{2}{*}{ Subject } & \multicolumn{2}{|c|}{ Glycine } & \multirow{2}{*}{$\frac{\text { Venous blood }}{\underset{\text { Ammonia }}{\text { rise }}}$} \\
\hline & $\begin{array}{l}\text { Total } \\
\text { dose }\end{array}$ & $\begin{array}{c}\text { Infusion } \\
\text { rate }\end{array}$ & \\
\hline G. S. & $\begin{array}{l}(m M) \\
194 \\
337 \\
376\end{array}$ & $\begin{array}{c}\left(m M / K_{8} / \text { min. }_{.}\right) \\
0.07 \\
0.11 \\
0.13\end{array}$ & $\begin{array}{c}\text { (us./ml.) } \\
3.3 \\
6.5 \\
7.8\end{array}$ \\
\hline J. F. & $\begin{array}{l}265 \\
348 \\
374\end{array}$ & $\begin{array}{l}0.07 \\
0.10 \\
0.11\end{array}$ & $\begin{array}{l}1.1 \\
2.1 \\
3.1\end{array}$ \\
\hline G. A. & $\begin{array}{l}158 \\
275\end{array}$ & $\begin{array}{l}0.06 \\
0.10\end{array}$ & $\begin{array}{l}0.4 \\
2.2\end{array}$ \\
\hline W. M. & $\begin{array}{l}160 \\
245\end{array}$ & $\begin{array}{l}0.04 \\
0.06\end{array}$ & $\begin{array}{l}0.4 \\
4.3\end{array}$ \\
\hline W. P. & 288 & 0.11 & 1.0 \\
\hline
\end{tabular}

However, addition of L-arginine in small amounts prevented or markedly reduced the blood ammonia changes. It should be noted that the similar but non-toxic Solution B-1 contains somewhat more L-arginine than was necessary to modify the ammonia-forming potential of mixture B-2.

\section{Glycine-ammonia production}

In further studies of ammonia production from intravenous amino acid infusion glycine was utilized. The influence of the rate of glycine administration on the blood ammonia rise is indicated in Table II. With increasing rates of glycine administration, a greater blood ammonia response was noted. Because all infusions lasted 60 minutes, a comparison of the effect of total dose versus rate of glycine administration cannot be made.

Some degree of fasting in the amino acid recipient is usually required to produce a blood ammonia rise on amino acid administration, at least under the conditions in which these studies were conducted. A comparison of the blood ammonia response at several levels of protein feeding is illustrated in Figure 4.

\section{Protective effect of L-arginine}

Intravenous administration of L-arginine immediately prior to glycine infusion was capable of preventing the ammonia rise in fasted subjects (Figure 5). A partial inhibition of the ammonia rise was produced by suboptimal amounts of argi- 


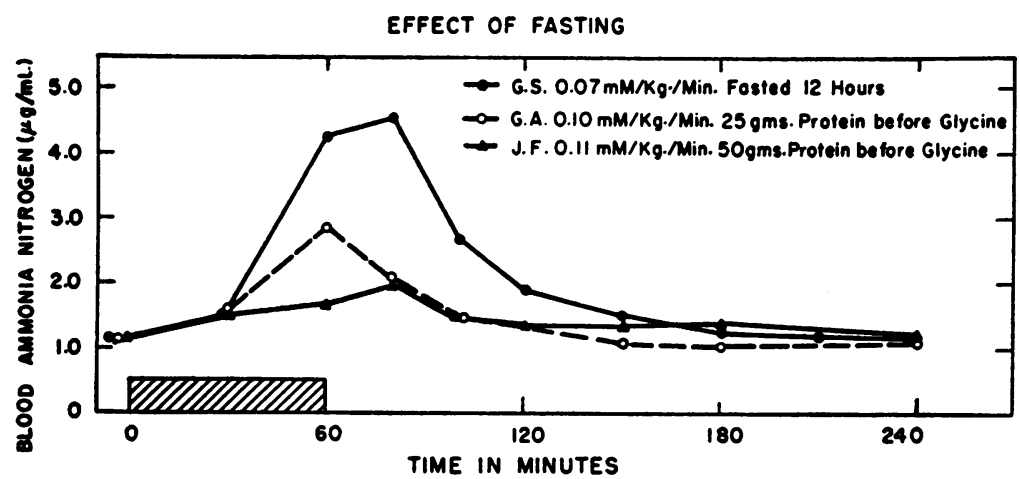

Fig. 4. Eftect of Fasting on the Blood Ammonia Response to Glycine ADMINISTRATION

Protein feedings were given to G.A. and J.F. two hours prior to the 60 minute glycine infusions. All three subjects, when fasted equally, had had equivalent blood ammonia rises with these amounts of glycine.

nine. The amount of $L$-arginine required to modify the blood ammonia rise was influenced by the amount of amino acid administered, as is seen with subject G.S., Figure 5. When an increased amount of glycine was given, more arginine was needed to reduce the blood ammonia changes. The characteristics of the amino acids administered may also influence the arginine requirement. This is suggested by the apparently lower arginine requirement of the L-amino acid mixture than of the single amino acid glycine. The quantity of arginine needed to modify the blood ammonia response is also influenced by the extent of protein deprivation. Although a 12 hour fast is usually adequate to produce a deficiency state demonstrable under the conditions of these experiments, a 36 hour period without protein intake was routinely employed in these studies.

The rapidity and effectiveness of L-arginine in altering a blood ammonia rise that is already underway were investigated by withholding the $\mathrm{L}$-arginine injection until the forty-fifth minute of a 60

EFFECT OF L-ARGININE ON THE BLOOD AMMONIA RESPONSE TO GLYCINEINFUSION

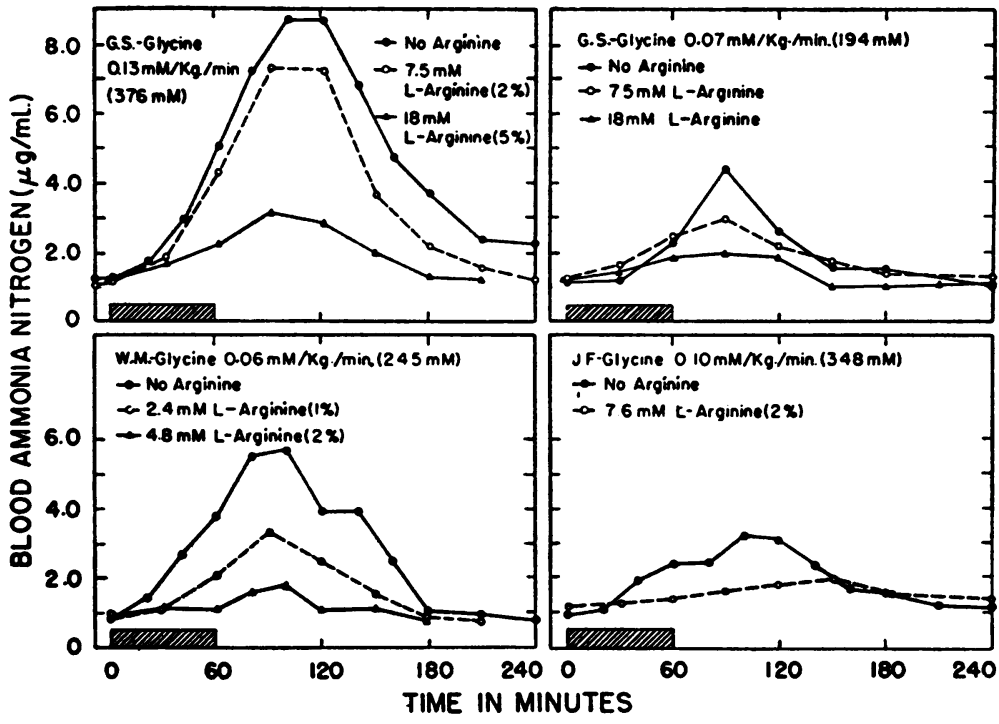

Fig. 5. Effect of L-Arginine on the Blood Ammonia Response to Glycine INFUSION

L-arginine was injected intravenously immediately prior to the glycine infusion. 


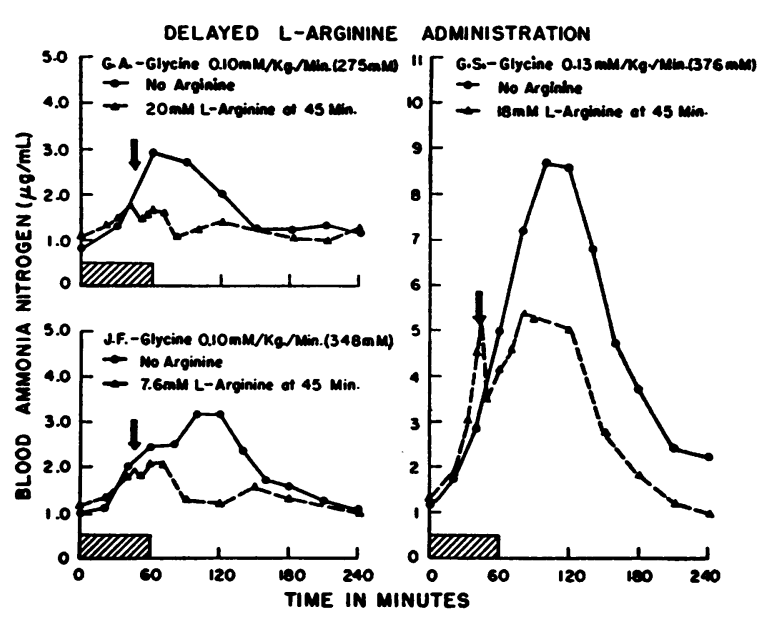

Fig. 6. Effect of Delayed l-Arginine Injection on the Blood Ammonia Rise Already Underway from Glycine Administration

The shaded area indicates the duration of glycine infusion. The time of arginine injection is indicated by the arrow $(\downarrow)$.

minute glycine infusion. As is seen in Figure 6 (and Figure 3), the L-arginine injection was capable of preventing further blood ammonia rise and inducing an early return to normal levels. The effectiveness of the L-arginine injection evidently depends upon the quantity of L-arginine injected and the amount of amino acid infused.

Arginine storage was investigated by administration of L-arginine some hours prior to glycine infusion. The subsequent ammonia rise'was compared with the response when the same amount of L-arginine was injected immediately prior to glycine administration. Figure 7 demonstrates an evident capacity for arginine storage within the body.

\section{L-ornithine activity}

L-ornithine (18 $\mathrm{mM})$ injected intravenously prior to a glycine infusion in subject G.S. inhibited the blood ammonia rise in a manner similar to L-arginine. L-ornithine also reduced the blood ammonia rise when incorporated in the amino acid mixture B-2 (Figure 3 ).

\section{DISCUSSION}

\section{Ammonia formation}

Blood ammonia elevation in association with amino acid administration has been demonstrated previously in animal studies. Ammonia release into the blood of dogs following glycine administration has been reported by Bornstein (8), Polonovski, Boulanger, and Bizard (9), Doolan, Harper, Hutchin, and Alpen (10), and Harper, Najarian, and Silen (11). Greenstein and coworkers, investigating the toxicity of mixtures and individual $\mathrm{L}$-amino acids administered intraperitoneally to rats, demonstrated that a marked blood ammonia rise may accompany the toxic manifestations of L-amino acid administration and suggested that the ammonia formation was one aspect of L-amino acid toxicity $(12,13)$. Kamin and Handler (14), administering amino acids parenterally to dogs, infused a mixture of amino acids (all as D-L forms) that did not contain arginine. This mixture was uniformly lethal in one hour with terminal blood ammonia levels of 30 to 40 micrograms per $\mathrm{ml}$. The effect of arginine addition was not studied. Although the authors attributed the marked blood ammonia rise to deamination of the D-amino acids, it is now appreciated that ammonia may also be an intermediate in L-amino acid metabolism.

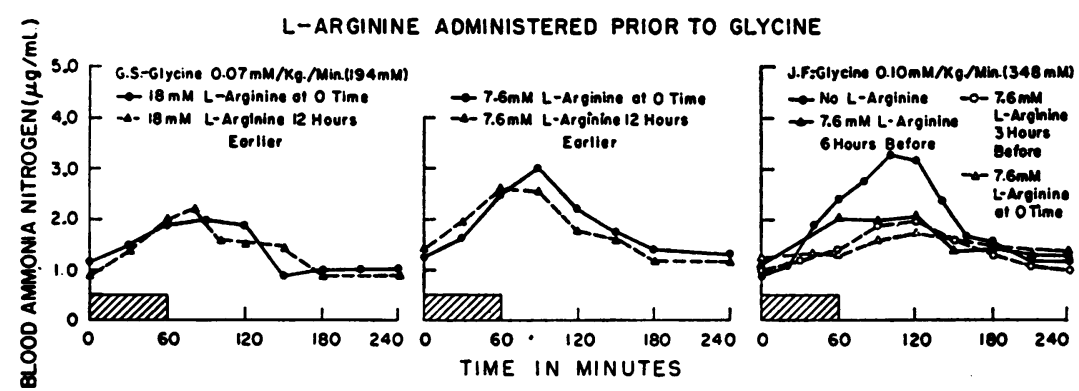

Fig. 7. Comparison of the Blood Ammonia Response to Glycine Infusion When l-Arginine Was Injectrd at Various Intervals Prior to Glycine AdMconsistration 
Ammonia formation in man was postulated by Doolan to explain the toxic effects he observed with rapid glycine infusion (10). His normal fasting subject experienced malaise, nausea, vomiting and a pyrogenic-type reaction with marked weakness, shaking chills, headaches and temperature to $100.8^{\circ} \mathrm{F}$. Blood ammonia levels were not measured in Doolan's patient nor in our patient who developed coma without marked nausea or vomiting, although narcotic administration may have suppressed these manifestations in the latter instance. Whether all of the toxic symptoms seen in the patient receiving the amino acid mixture B-2 are attributable to ammonia toxicity and whether advanced debility contributed to the response is uncertain. In our studies with controlled blood ammonia elevation from administration of glycine or an L-amino acid mixture, nausea and retching accompanied the blood ammonia rise. No gross neurologic or cardiovascular changes were noted. Nausea has also been noted when blood ammonia elevation was produced by ammonium chloride infusion (15). While other metabolic products from amino acid administration may be toxic, ammonia formation with resulting elevated blood ammonia levels is one aspect of amino acid toxicity.

The amount of amino acid administered during the studies reported here was found to determine, in part, the blood ammonia response and toxicity. The relative importance of total dose versus rate of administration was not assessed since all of the studies were conducted with 60 minute amino acid infusions. Administration of $0.10 \mathrm{mM}$ glycine per $\mathrm{Kg}$. per minute always produced an ammonia rise in our fasted subjects. As little as 0.06 $\mathrm{mM}$ per $\mathrm{Kg}$. per minute for 60 minutes has produced significant blood ammonia elevation. Doolan's subject developed toxicity when glycine was given at an average rate of $0.67 \mathrm{mg}$. N $(0.05 \mathrm{mM}$ glycine) per $\mathrm{Kg}$. per minute for 104 minutes. Two other subjects receiving smaller doses noted only mild toxic symptoms. In the present studies there was some individual variation in the blood ammonia response to glycine. Recalculation of the dosage on the basis of body surface area did not significantly alter the differences.

It should be noted that the patient in whom the toxic effects of the arginine-free amino acid mixture were first observed had been on a low-arginine diet in the previous months. Similarly, the rise in blood ammonia could be induced most easily in fasting subjects. The previous nutritional state, especially as to arginine intake, may have considerable influence on the susceptibility of development of blood ammonia changes following intravenous amino acid administration.

A comparison of the ammonia forming potential of the two solutions used in these studies is not entirely feasible because the subjects given the L-amino acid mixture had not been fasted from protein quite as long as those receiving glycine. However, different rates of ammonia formation are indicated if the sequence of ammonia changes are compared when equivalent blood ammonia elevations were induced by the two solutions. With glycine the 60 minute blood ammonia level is higher and the maximum rise is obtained earlier than with the B-2 mixture which is composed principally of L-alanine. This is compatible with the observations in the rat where individual L-amino acids produced characteristic and differing blood ammonia responses after intraperitoneal injection (12). The relative contribution of the infused amino acid nitrogen to the $\mathrm{NH}_{r}-\mathrm{N}$ that actually reaches the blood is uncertain. However, it is not unreasonable to assume that some ammonia comes from the administered amino acids. In experimental animals, both glycine and L-alanine are rapidly removed by the liver and kidneys after intravenous injection (16), and ammonia formation and release into the blood occur in both these organs $(8,9)$.

\section{L-arginine activity}

The striking activity of $\mathrm{L}$-arginine in preventing or reducing the blood ammonia rise and toxicity with amino acid infusions suggests that this effect may be mediated by the Krebs-Henseleit urea cycle $(3,17)$. Compatible with this explanation are the results of studies in dogs with the L-amino acid mixture B-2 (4). L-ornithine and L-citrulline as well as L-arginine protected against the toxicity and blood ammonia rise while L-glutamic acid was ineffectual. Intravenous administration of the amino acid mixture without arginine produced a distinct sequence in the rise and fall of amino acids, ammonia, and urea in the blood with peak levels being reached in that order. Such changes are compatible with a sequence of amino acid removal from 
the blood and metabolism to produce ammonia, ammonia production temporarily exceeding the capacity for ammonia removal and, finally, cumulative urea synthesis resulting in an increased blood urea. By measuring both the urine urea output and plasma urea rise, it was possible to demonstrate that urea production was more rapid when L-arginine was included in the amino acid mixture and that the increased urea was more than would be contributed by direct metabolism of the administered arginine. Similar effects of L-arginine on the blood ammonia and urea concentrations have been demonstrated following administration of L-amino acids to rats (13) and glycine to dogs (18).

L-arginine was effective in man when administered by intravenous rapid injection or slow infusion. The protective action of dietary protein suggests that orally administered arginine would also be active. L-arginine was active if included in the amino acid infusion or if injected shortly before. There is some evidence that administration of small amounts of arginine may be less effective if given more than three to six hours prior to the ammonia-inducing amino acids. This has been demonstrated somewhat more clearly in dogs (4) than in the present studies in man. If the amino acid infusion and blood ammonia rise are already underway, L-arginine administration apparently acts rapidly to modify the extent and duration of the ammonia rise.

The amount of L-arginine needed to modify significantly the blood ammonia changes resulting from amino acid infusion in man will vary with the amount, rate and ammonia-forming potential of the administered amino acid(s) and with the nutritional state of the host. In these studies with glycine and with a mixture of L-amino acids, 5 to 10 millimoles (approximately 1 to 2 grams) of L-arginine effectively reduced blood ammonia changes when the tendency to ammonia formation was not great. However, when the blood ammonia change was likely to be large, as much as 20 millimoles (4 grams) of L-arginine was only partially effective.

No toxicity was observed with L-arginine $\cdot \mathrm{HCl}$ administration either as a $20 \mathrm{mM}$ intravenous injection in three minutes or as an $180 \mathrm{mM}$ (38 grams) infusion over 120 minutes. L-ornithine$\mathrm{HCl}$ was non-toxic when given as a $20 \mathrm{mM}$ injection.
The rates of amino acid administration in these studies do not markedly differ from those of clinical intravenous alimentation. Infusion in an hour of a liter of typical 5 per cent protein hydrolysate (containing 6 grams of nitrogen with 4.2 grams as alpha amino nitrogen) to a $50 \mathrm{Kg}$. patient represents a rate of $0.10 \mathrm{mM}$ amino acid per $\mathrm{Kg}$. per minute and is in the range utilized in these studies. Giving a fairly complete amino acid mixture may have markedly different effects from those associated with an unbalanced mixture or a single amino acid. The major effect observed in these studies seems to be related to the presence or absence of $\mathrm{L}$-arginine.

The presence of neoplasm in these subjects is not thought to alter the general application of these findings to man. The extent that hepatic disease will affect the response to amino acid administration is uncertain. In our patient with conspicuous hepatic disease (W.M.), the ammonia rise developed readily with glycine administration, and L-arginine was effective in reducing this rise. Kirk did not observe any marked difference from normal in the metabolism of orally administered glycine in patients with hepatic disease (19).

Intravenous amino acid administration has been utilized as a liver function test $(20-22)$ and in renal tubular function studies (10), and intravenous glycine has been proposed as a means of combating hypothermia (23). Purified amino acids given intravenously have been utilized in physiologic and nutritional studies in man. Such situations emphasize the need for recognition of the role of L-arginine. Although L-arginine may not be "essential" to the maintenance of nitrogen balance in healthy young adults fed an oral diet, it would seem to be important to regard L-arginine (or a related amino acid) as "essential" in the prevention of one aspect of intravenous amino acid toxicity, that of excessive ammonia in the blood.

\section{CONCLUSIONS}

1. Marked blood ammonia rise and toxicity have been demonstrated in man with intravenous administration of glycine or an L-amino acid mixture free of $\mathrm{L}$-arginine but complete in all the "essential" amino acids.

2. The blood ammonia rise with intravenous amino acid administration appears to depend on the amount of amino acid and rate at which it is given, the ammonia-forming characteristics of the 
amino $\operatorname{acid}(s)$ infused, and the state of nutrition of the host, particularly in relation to recent arginine intake.

3. $\mathrm{L}$-arginine was effective in reducing the blood ammonia rise and associated toxicity developing from these intravenous amino acid infusions. L-arginine may be given as a part of the infusion or by intravenous injection immediately or some hours prior to the amino acid administration. If amino acid administration and the blood ammonia rise are already underway, injection of adequate amounts of L-arginine will rapidly reduce the blood ammonia rise.

4. The findings indicate that a functioning metabolic pathway, requiring L-arginine and consistent with the operation of the Krebs-Henseleit cycle, is an important metabolic route when large amounts of amino acids are administered to man.

\section{ACKNOWLEDGMENT}

The author wishes to thank Miss Patricia McCoy for skillful technical help during these studies.

\section{REFERENCES}

1. Rose, W. C., Amino acid requirements of man. Federation Proc., 1949, 8, 546.

2. Gullino, P., Winitz, M., Birnbaum, S. M., Otey, M. C., Cornfield, J., and Greenstein, J. P., Toxicity of essential amino acid mixtures with special reference to the protective effect of L-arginine. Arch. Biochem. \& Biophys., 1955, 58, 255.

3. Greenstein, J. P., Winitz, M., Gullino, P., and Birnbaum, S. M., The prevention of ammonia toxicity by $\mathrm{L}$-arginine and related compounds. Arch. Biochem. \& Biophys., 1955, 59, 302.

4. Fahey, J. L., McCoy, P. F., and Perry, R., Blood ammonia formation and toxicity with intravenous administration of an L-amino acid mixture: The role of L-arginine. Am. J. Physiol., In press.

5. Greenstein, J. P., The resolution of racemic alphaamino acids. Advances in Protein Chem., 1954, 9, 121.

6. Seligson, D., and Seligson, H., A microdiffusion method for the determination of nitrogen liberated as ammonia. J. Lab. \& Clin. Med., 1951, 38, 324.

7. Seligson, D., and Hirahara, K., The measurement of ammonia in whole blood, erythrocytes, and plasma. J. Lab. \& Clin. Med., 1957, 49, 962.

8. Bornstein, A., Uber die Rolle von Leber und Darm bei der Desaminierung der Aminosäuren. Biochem. Ztschr., 1929, 214, 374.

9. Polonovski, M., Boulanger, P., and Bizard, G., Formation d'ammoniaque aux dépens des acides aminés dans le rein du chien in vivo. Compt. rend. Acad. d. Sc., 1934, 198, 1815.
10. Doolan, P. D., Harper, H. A., Hutchin, M. E., and Alpen, E. L., The renal tubular response to amino acid loading. J. Clin. Invest., 1956, 35, 888.

11. Harper, H. A., Najarian, J. S., and Silen, W., Effect of intravenously administered amino acids on blood ammonia. Proc. Soc. Exper. Biol. \& Med., 1956, 92, 558.

12. Gullino, P., Winitz, M., Birnbaum, S. M., Cornfield, J., Otey, M. C., and Greenstein, J. P., Studies on the metabolism of amino acids and related compounds in vivo. I. Toxicity of essential amino acids, individually and in mixtures, and the protective effect of L-arginine. Arch. Biochem. \& Biophys., 1956, 64, 319.

13. du Ruisseau, J. P., Greenstein, J. P., Winitz, M., and Birnbaum, S. M., Studies on the metabolism of amino acids and related compounds in vivo. IV. Blood ammonia and urea levels following intraperitoneal administration of amino acids and ammonium acetate, and the effect of arginine thereon. Arch. Biochem. \& Biophys., 1956, 64, 355.

14. Kamin, H., and Handler, P., Metabolism of parenterally administered amino acids. II. Urea synthesis. J. Biol. Chem., 1951, 188, 193.

15. Seegmiller, J. E., Schwartz, R., and Davidson, C. S., The plasma "ammonia" and glutamine content in patients with hepatic coma. J. Clin. Invest., 1954, 33, 984.

16. Awapara, J., and Marvin, H. N., The relative absorption of intravenously administered amino acids by the liver, kidney, and muscle of the rat. J. Biol. Chem., 1949, 178, 691.

17. Krebs, H. A., and Henseleit, K., Untersuchungen über die Harnstoffbildung im Tierkörper. Hoppe Seyler's Ztschr. f. physiol. Chem., 1932, 210, 33.

18. Najarian, J. S., and Harper, H. A., Comparative effect of arginine and monosodium glutamate on blood ammonia. Proc. Soc. Exper. Biol. \& Med, 1956, 92, 560.

19. Kirk, E., Amino acid and ammonia metabolism in liver diseases. Acta med. Scandinav., 1936, Suppl. 77.

20. Kohn, R., and Stein, L., ther den Ablauf der Blutammoniakkurve nach intravenöser Glykokollbelastung bei Leberkankheiten. Klin. Wchnschr., 1935, 14, 233.

21. Lyttle, J. D., Goettsch, E., Greeley, D. M., Grim, W. M., and Dunbar, P., Amino acid studies. II. Plasma amino acid retention, as evidence of impaired liver function. Investigations in children with nephrosis and liver disease. J. Clin. Invest., 1943, 22, 169.

22. Lewis, J. H., Taylor, F. H. L., and Davidson, C. S., Tolerance to intravenously administered protein hydrolysate in severe human liver cirrhosis. Am. J. M. Sc., 1947, 214, 656.

23. Beavers, W. R., and Covino, B. G., Immersion hypothermia: Effect of glycine. Proc. Soc. Exper. Biol. \& Med., 1956, 92, 319. 